\title{
Food Engineering within Sciences of Food
}

\author{
A.E. KOSTAROPOULOS \\ a Emeritus Professor: Agricultural University of Athens. Iera Odos 75, 11855 Athens, Greece \\ ak@aua.gr \\ TEL: +2106821503 \\ FAX: +2106847111
}

Received: 30 March 2012; Published online: 18 October 2012

\begin{abstract}
The aim of this paper is to clarify the identity of food engineering in sciences of food. A short historical description of the evolution of the branch in the Anglo Saxon and the Continental educational systems is given. Furthermore, the distinction of basic definitions such as food science, food science and technology, food technology, and food engineering is made. Finally, the objectives of food engineering within the branch of sciences of food are described.
\end{abstract}

Keywords: Food Engineering; Food Science; Food Technology

\section{Introduction}

Food engineering was firstly introduced in the western countries, in the Technical University of Karlsruhe in 1948, (Kuprianoff, 1962). At that time it was decided to establish a curriculum for engineers in the food Industry. The new branch was called Lebensmitteltechnik (food technique) and later Lebensmittel Ingenieurwesen (food engineering). It belonged to the Faculty of Verfahrenstechnik (process technique/engineering). Basically, it was a food oriented chemical engineering branch of the sciences relating to food, incorporating additionally food chemistry, physical chemistry and in a minor scale, food microbiology and biology.

At the same time in the rest of Europe and in the USA, two main branches were involved in the science of food: food chemistry and food technology. The latter was introduced in the USA shortly before the $2^{\text {nd }}$ World War, and was to a great extent, a further development of food chemistry including a knowledge of microbiology and agricultural engineering. Then, in the Anglo-Saxon countries, food technology was fur-

Copyright (C)2012 ISEKI-Food Association (IFA) ther evolved to food science and technology. This included two main branches: food science (representing mainly food chemistry and food microbiology), and food engineering which initially was related to agricultural engineering (Karel, 1997) and then successively also incorporated many subjects of chemical engineering such as e.g. unit operations.

\section{Relation of Food Engineering to Anglo-Saxon and Continental Chemical Engineering}

Soon it was realized that the Anglo-Saxon type of food engineering was not the same as that of Germany. The reason was that the Anglo-Saxon type of chemical engineering did not exist at all in Germany (Koebel \& Hammer, 1966)! This was due to developments that occurred just after the $1^{\text {st }}$ World War. The German industry, which was the main supplier of chemical products internationally, was based on the cooperation of: a) chemical technology (Chemische Technologie), which was a development towards applied 
chemistry and

b) Process engineering (Verfahrenstechnik) which was more or less a mechanical engineering approach to chemical technology.

During the world wars, due to restrictions in the import of German chemical products, this gap was covered in the USA by introducing chemical engineering, a branch that fell between chemistry and mechanical engineering. In Germany, the gap between chemistry and the designers of apparatus for the chemical industry was closed by moving process engineering even closer to chemical technology (Figure 1).

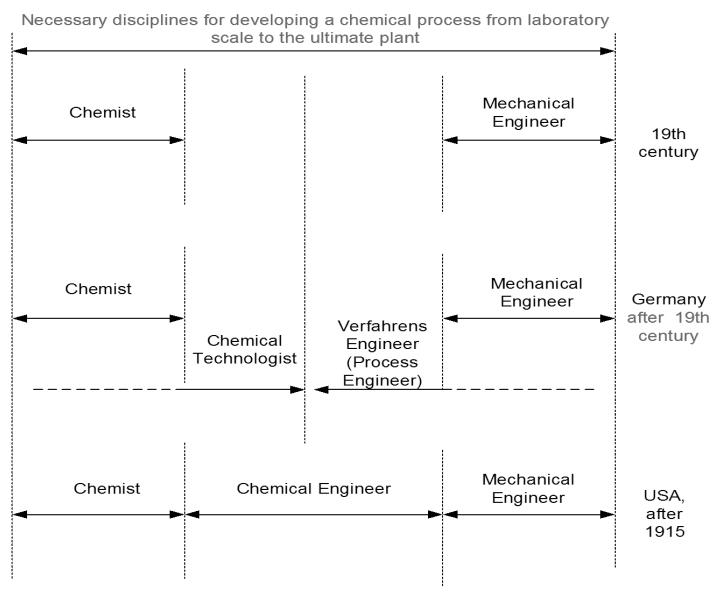

Figure 1: Development of Chemical Engineering in USA and Germany

In the food sector, these solutions later resulted in, that according to their origin, the AngloSaxon type of food engineer being more strongly oriented towards chemistry, while the German type, towards mechanical engineering (Rietema, 1966). However, the problem continues to exist because basic terms such as engineering, technology and technique, (and consequently food engineering, food technology and food technique) still are not very clear! Engineering e.g. in Europe, is understood as a branch mainly based on the following disciplines: mathematics, chemistry, thermodynamics, fluid mechanics, and technical mechanics (static and strength of materials and dynamics/momentum) (Sellers, 1966). However in recent years, especially in USA, engineering has taken on a much broader meaning. It is used in branches that are not based on the afore-mentioned disciplines; such examples are: genetic engineering, metabolic engineering, molecular engineering, cost engineering, social engineering, behavioural engineering, etc. This misuse is partially due to the misunderstanding of the origin of the definition for engineering.

\section{Definition of the terms Engineering and Technology}

Engineering derives from the Latin word, ingenium, meaning: "talent, high mental ability" ("Online Etymology Lexicon," 2012; "The Concise Oxford Dictionary," 1976). This is probably based on the Greek Words $\varepsilon \nu(\mathrm{en}=\mathrm{in})$ and rírvo$\mu \alpha_{l}$ (gignome), related to gigno, meaning to bear, to find out through mental effort, which term was also introduced in the Latin language (Ullrich \& Koumanoudi, 1984). Thus in both languages (Greek and Latin), engineering has to do with invention requiring mental ability. This is the reason that this term was and continues not to be restricted only for people with a special type of education, but also craftsmen and other labour involved persons may call themselves engineers. Therefore, some countries such as e.g. Germany and Greece, distinguished the engineers holding a technical university degree by introducing the title "Diploma Engineer".

Technology is also a not very well defined term allowing its use by scientists of very different education (Sellers, 1966; Kuprianoff, 1966). There are many interpretations of the word that is again composed by two Greek words: Tर́x $\sim \eta$

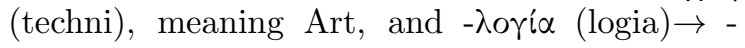
logy (often via French -logie or Medieval Latin logia), from root of $\lambda \varepsilon^{\prime} \gamma \varepsilon\llcorner\nu$ (legein), i.e., to speak, which is, "the character or department of one who speaks or treats a certain subject", also meaning "a speaking, discourse, treatise, doctrine, theory, science" ("Online Etymology Lexicon," 2012). Therefore technology may be defined as the systematic treatment of a technique or an art, using experience and knowledge to achieve a practical objective benefit (Ullrich \& Koumanoudi, 1984) and it often foregoes engineering and science. Technique is the practical skill that leads to reasonable achievement of 
goals over procedures (which many times are not self evident). Generally speaking, technology is closer to experience than technique.

With respect to food, food technology (Lebensmitteltechnologie) is the application of methods for treatment conservation, processing or transformation of foods, while food technique (Lebensmitteltechnik) refers to the application of the means for the realization of technical food processes in industrial scale. Food Engineering is thus part of the food technique (Kuprianoff, 1962). However, this branch is further more complex as it combines two very different items: foods, which are products of biological origin, with engineering dealing with physical (in a broader sense) skills.

\section{Branches of Sciences of Food and the objectives of Food Engineering}

A new classification of basic food branches, as the one indicated in Figure 2 could be, perhaps, useful. Basic elements of this classification are the use of sciences of food as an overall term instead of the term food science and technology because in the actual definition, food science, is restricted only to chemistry, microbiology, and nutrition and it excludes food engineering and food technology, although these are also scientific branches. It is proposed that the sciences of food includes four main branches:

1. Engineering sciences

2. Chemical sciences

3. Biosciences

4. Nutritional sciences.

With respect to the above distinctions between technique and technology, Engineering Sciences to be composed by:

1.1. Food engineering (food technique)

1.2. Food Technology
1.1. Food Engineering to include:

1.1.1. Food engineering principles to deal with:

- Basic elements of food processing, transformation, conservation (e.g. mechanical processing operations, unit operations, refrigeration, novel methods applied to food such as nanotechnology, electric methods, etc).

- Materials science (e.g. properties of food, and other materials coming in contact with food).

- Food equipment.

1.1.2. Plant design to deal with operations of whole food processing units, including:

- Storage and logistics, conveying systems and transport, equipment for food.

- Auxiliary equipment and machinery (e.g. steam, water supply etc), CAM.

- Instrumentation and automatic control, environmental matters.

- Feasibility studies, environmental and economic aspects and modelling of establishing and operating food factories.

1.2. Food Technology to include:

1.2.1. Applied food processing to deal with:

- Processes involved in manufacturing of specific foods such as e.g.: meat, fish, poultry, milk, plant products/ cereals, fat/ oil, etc.

- Reference to special conditions, features and facts including besides special processing matters, any special equipments required. 


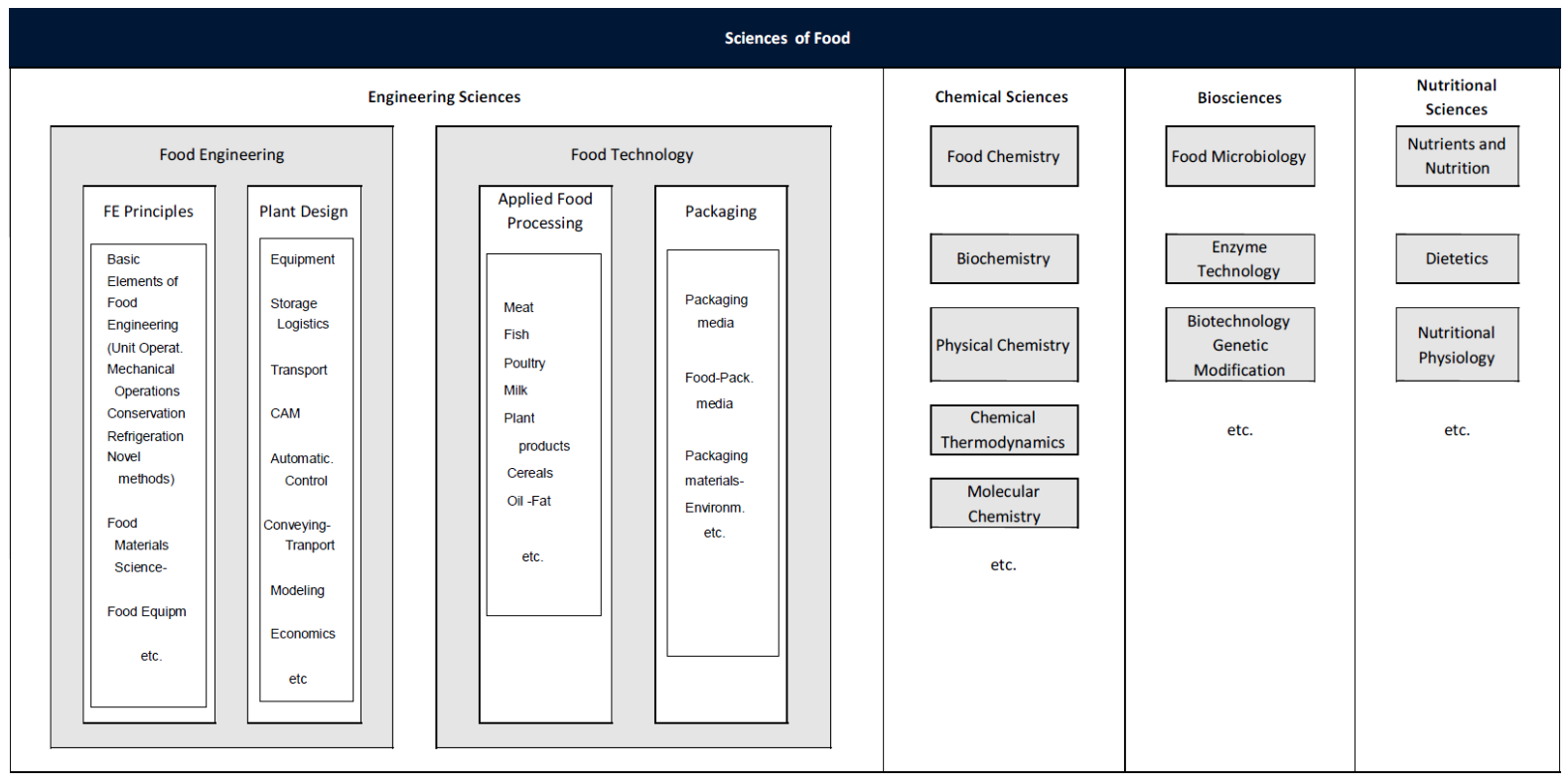

Figure 2: Classification of food branches

1.2.2 Packaging to deal with:

- Packaging materials and media for food.

- Technical impact of different types of packages and packaging (e.g. interaction between food and packaging, steadiness and strength of packages, etc.).

- Environment interaction on packages.

- Packaging systems and machinery.

Besides the branches indicated in (Figure 2), it should be mentioned that in sciences of food, the roles of consumer sciences and sensory analysis are also important. These two branches have not been included in (Figure 2), as they are actually involved in almost all branches described by it.

\section{Conclusions}

Food engineering is today, about 65 years after its introduction, a well established branch of food sciences. This scientific field of activity is worldwide. It is taught in a number of Universities and there are various committees, bodies, boards, scientific journals, etc., dealing with it. However, there is still some ambiguity concerning definitions related to the overall scope of the branch. This is partially due to basic differences between the Anglo-Saxon and the Continental system of education. Here an attempt has been made to classify several branches of the sciences of food. In any case, it must always be kept in mind, that all food related branches must have one certain goal: to provide proper safe and adequate nutrition.

\section{Acknowledgements}

Thanks to Professor G.D.Saravacos for useful and important comments. 
Food Engineering within Sciences of Food. $\mid 113$

\section{References}

Karel, M. (1997). In food engineering 2000. In P. Fito, E. Ortega-Rodríguez, G. BarbosaCánovas \& C. . Hall (Eds.), (Chap. The history and future of food engineering).

Koebel, H., \& Hammer, H. (1966). The growth of a new engineering branch: process engineering, (Chap. Ueber die Ausbidung des akademischen Nachwuchses für das Gebiet der Entwicklung technisch- chemischer Verfahren, pp. 15-19). La Communeauté Éuropéenne Culturelle des Étudiants en Chimie.

Kuprianoff, J. (1962). Sonderdruck aus der dechema-monographien band 46, (Chap. Besondere Aspekte der Lebensmitteltechnik, ausgezeigt am Beispiel der Mechanischen Verfahrenstechnik).

Kuprianoff, J. (1966). The growth of a new engineering branch: process engineering, (Chap. The process -engineer and the food industry, pp. 25-27). La Communeauté Éuropéenne Culturelle des Étudiants en Chimie.

Online Etymology Lexicon. (2012). Retrieved from http://www.etymonline.com/

Rietema, K. (1966). The growth of a new engineering branch: process engineering. La Communeauté Éuropéenne Culturelle des Étudiants en Chimie.

Sellers, E. (1966). The growth of a new engineering branch: process engineering, (Chap. Chemical engineering in Great Britain, in: pp. 20-22). La Communeauté Éuropéenne Culturelle des Étudiants en Chimie.

The concise oxford dictionary. (1976). Oxford University Press.

Ullrich, H., \& Koumanoudi, S. (1984). Greek latin lexicon. (Athens 1864). 